\title{
ESCULTURAS DE ITÁLICA APARECIDAS EN EL SIGLO XVIII
}

\section{ITALICS SCULPTURES FOUN IN THE 18TH CENTURY}

\author{
JOSÉ BELTRÁN FORTES*
}

\begin{abstract}
Resumen: Durante la segunda mitad del siglo XVIII las búsquedas de materiales arqueológicos en el yacimiento de Italica (Santiponce, Sevilla) fueron muy frecuentes, sobre todo, de esculturas e inscripciones romanas. No obstante, hay dudas sobre los lugares exactos donde se produjeron tales descubrimientos. Revisamos la documentación existente para establecer hipótesis sobre los lugares de descubrimientos, especialmente el foro de la ciudad romana, contextualizando tales materiales.

Palabras clave: Italica. Esculturas e inscripciones romanas. Siglos XVIII. Francisco de Bruna. Monasterio de San Isidoro del Campo, Santiponce (Sevilla).
\end{abstract}

\section{INTRODUCCIÓN}

En dos recientes trabajos que tratan las esculturas romanas procedentes de Italica (Santiponce, Sevilla) se ha planteado la cuestión de la localización de sus descubrimientos en el yacimiento y, por ende, la localización de ciertos topónimos históricos del sitio arqueológico. Supone un tema viejo en la tradición bibliográfica italicense, pero no por ello resuelto y que -como se veráha fluctuado según diversos estudios desde las pioneras páginas que le dedicó Antonio García y Bellido (1960) en su obra sobre Italica, como ocurre en otros muchos temas que tienen que ver con la arqueología italicense. En primer lugar, corresponde a la hipótesis que José

\footnotetext{
* Universidad de Sevilla
}

\begin{abstract}
During the second half of the Eighteenth Century the research of Archeological finds at the site of Italica (Santiponce, Sevilla) were very common, specially of Roman sculptures and inscriptions. However, there are reservations about the exact places where this finds are made. We look through the documents in order to establish a hypothesis about the places of the finds, specially the forum of the Roman city, contextualizing these materials.

Key words: Italica. Roman Sculptures and Inscriptions. Eighteenth Century. Francisco de Bruna. San Isidoro del Campo Monastery, Santiponce (Seville)
\end{abstract}

Manuel Rodríguez Hidalgo (2009a) plantea en el catálogo de la exposición de la nueva cabeza marmórea de divinidad femenina (Beltrán 2009b) aparecida en el yacimiento en el marco de una excavación arqueológica a comienzos del año 2008 (Rodríguez y Jiménez 2009). En segundo lugar, los datos contenidos en un trabajo de síntesis que yo mismo he elaborado sobre las esculturas romanas de Itálica, donde asimismo sintetizo las propuestas de localización de tales obras en diversas áreas del yacimiento (Beltrán 2010), pero dado el carácter de la publicación ello se hace sin la adecuada argumentación, lo que ahora pretendo subsanar.

Tras el estudio de Pilar León (1995), referido al estudio iconográfico y estilístico del conjunto escultórico de Itálica y a sus talleres de producción, se ha renovado recientemente el interés por el argumento con los nuevos trabajos de su alumno David Ojeda (2008; 2009 a 
y b) sobre la estatuaria ideal italicense de carácter público, en el marco de realización de su tesis doctoral, y queda como un apartado de enorme interés clarificar en lo posible el tema de la localización de las esculturas, para poder afianzar las hipótesis de propuestas de los programas en la ciudad romana. El carácter de excepcionalidad histórica y arqueológica de Itálica en el marco hispano (Caballos y León 1995) aporta un valor añadido a las posibles propuestas.

El problema estriba en que buena parte del conjunto escultórico, en concreto de las producciones que formarían parte de programas oficiales de función pública, han aparecido entre el siglo XVIII y la primera mitad del siglo XX, bien en el contexto de búsquedas o "excavaciones" faltas de todo rigor metodológico, de las que incluso no quedan ningún dato de localización fiable o muy escaso, o bien como descubrimientos ocasionales, con lo que la certeza sobre las procedencias concretas debe quedar en suspenso, simplemente podemos apuntar en muchos casos una plausibilidad de las hipótesis. Además, el que se hubieran concentrado en el entonces Museo de Antigüedades de Sevilla, por Real Orden de 1854, las esculturas italicenses de la colección de Francisco de Bruna que había expuesto en varios salones del Real Alcázar de Sevilla (s. XVIII) (Romero 1965; Beltrán 2001 y 2003; Cano 2003; López Rodríguez 2010), uniéndose con las procedentes de las excavaciones de Ivo de la Cortina (1840), determinó asimismo cierta confusión entre las procedentes de uno y otro lote, ya que en el citado Museo se elaboró un primer catálogo de piezas arqueológicas sólo en 1889 , sin poder discriminar en muchos casos las correspondientes a uno y otro lotes, sobre todo si se trataba de fragmentos escultóricos. Nosotros nos centraremos especialmente en las piezas más significativas que por su singularidad, dimensiones o conservación llamaron más la atención y fueron referidas o incluso dibujadas, asociadas a topónimos de procedencia en algún caso. Incluso en estos casos se han arrastrado equívocos en los datos de procedencia en algún caso, por evidentes errores, o bien se ha dudado sobre la localización del topónimo concreto.

\section{RELACIÓN DE PIEZAS ITALICENSES SOBRE LAS QUE CONSTA O SE DEDUCE FECHA Y/O LUGAR DE DESCUBRIMIENTO EN EL SIGLO XVIII}

Fue Antonio García y Bellido quien primero ordenó la secuencia de descubrimientos y excavaciones en Itálica, haciendo de forma meritoria una "historia continuada" desde la arqueología tardoantigua a las citas medievales sobre el yacimiento y la historia de las vicisitudes de su descubrimiento y estudio durante los siglos XVI-XX (García y Bellido 1960: 49-66), aunque en el caso concreto de la procedencia de algunas de las esculturas, que seguía lógicamente las procedencias dadas en ocasiones en el citado catálogo del Museo de Sevilla de 1887 o una tradición no documentada sobre otras piezas (García y Bellido 1960: 138-157), se conozcan ahora nuevos datos documentales que obliguen a cambiar algunas adscripciones o a que podamos concretar más las referencias del autor. Tuvo el gran mérito de ordenar la secuencia básica de ese descubrimiento arqueológico de Itálica. Síntesis generales de los trabajos realizados sobre Itálica son posteriormente las elaboradas por Pilar León (1993), A. Caballos, J. Marín y J. M. Rodríguez Hidalgo (1999: 39-50) $\mathrm{y}$, especialmente, por su mayor amplitud y minuciosidad, J. M. Luzón (1999). Asimismo debemos destacar un trabajo realizado específicamente sobre la historiografía de la estatuaria de Itálica (Rodríguez, Escobar y García 1991) y, sobre todo, el análisis de N. Chisvert (1987-1988), pues se trató de un amplio intento de localización de los topónimos recogidos en las fuentes escritas de los siglos XVIII y XIX, pero de conclusiones equívocas .

A nuestra intención, interesa ahora presentar una lista ordenada de descubrimientos y conformación de colecciones, así como de adscripciones de algunos conjuntos a áreas de la ciudad, aunque parcialmente ha sido hecho ya en los dos trabajos citados al inicio del trabajo y, especialmente, en la espléndida monografía ya citada de Luzón (1999).

Aparte de las piezas que fueron reutilizadas en la construcción del Monasterio de San Isidoro del Campo, propietario de todos los terrenos del yacimiento hasta las desamortizaciones del XIX (AAVV 2002), la primera colección de esculturas e inscripciones de Itálica se forma en el propio monasterio durante el siglo XVIII, fruto de las aficiones ilustradas de algunos de los monjes como el padre José Moscoso o Fernando de Zevallos (Luzón 2003; Rodríguez Hidalgo 2004), que se colocaron especialmente en el apeadero, en lo que ha sido denominado como "el depósito eclesiástico mejor conocido y estudiado gracias a los diversos viajeros y a los dibujos de las piezas encontradas" (Salas 2007: 143).

Las primeras excavaciones referidas son las que lleva a cabo Manuel Martí en 1711, cuando está en Sevilla en la "Casa de Pilatos" durante varios años por encargo del Duque de Medinaceli para ordenar y estudiar su biblioteca y antigüedades que aún quedaban en el palacio sevillano, pero desconocemos qué materiales 
pudo obtener en sus trabajos, amén del dibujo del anfiteatro que envió al benedictino Bernard de Montfaucon para ser incluido en L'Antiquité expliquée et representée en figures (1717-1724) (Rodríguez Hidalgo 1991; Luzón 1999: 33ss.; Beltrán 2003).

El siguiente hito lo marcan los trabajos llevados a cabo en 1753 en el anfiteatro italicense bajo las órdenes de Miguel José de Espinosa, Conde del Águila, y que serían realizados por Pedro de San Martín y Lara, arquitecto mayor del cabildo de Sevilla, y el dibujante Juan Espinal, a requerimiento del padre Enrique Flórez (Luzón 1999: 36 ss.), quien incluyó al año siguiente los resultados en el volumen XII de su España Sagrada (Flórez 1754: 227-234). De forma paralela se estaban llevando a cabo excavaciones en otro sector del yacimiento, denominado "Los Palacios", según refiere el padre Zevallos en su obra La Itálica, que -como es sabido- será llevada a la imprenta por vez primera en 1886, pero que fue redactada a finales del siglo XVIII:

“...por los años de 1753 , cavándose en el sitio llamado Los palacios, se sacaron dos grandes pedestales, que habían sostenido estatuas dedicadas la una al emperador César M. Aur. Probo Pio \& $\&^{\mathrm{a}}$, siendo Procurador de la república de Itálica, que la dedicaba, Aurelio Julio; y la otra fue dedicada por la misma república Italicense al emperador César M. Aur. Caro $\&^{\mathrm{a}} \ldots$ El P. Mtro. Fr. Enrique Flórez publicó ambas piedras, y sus inscripciones el año siguiente en el tomo 12 de su España Sagrada" (Zevallos 1886: 2526; cfr. Matute 1827: láms. 2 y 17) (figs. 1 y 2).

E indica a continuación:

"Después el año 1760 en el mismo sitio de los Palacios se halló otra inscripción en un pedestal de mármol blanco más entero, y mejor conservado, que los dos antecedentes. Es una dedicación hecha al Emperador Floriano, en su brevísimo tiempo por la misma república Italicense" (Zevallos 1886: 26).

No obstante, no todo se recuperaba y el destrozo debía ser importante, como deja constancia el intento de F. de Bruna de detener los ataques contra el anfiteatro para reutilizar sus materiales como piedra de construcción, en solicitud al Conde del Águila de 1771 (Luzón 1999: 44). Todavía algunos años después tenemos la referencia del viajero S. Sánchez Sobrino (1774: 70), de que "acababan los trabajadores de hacer pedazos una media estatua que me pareció ser de Trajano... que permanecía casi entero" (García y Bellido 1960: 55), lo que constata además que los descubrimientos escultóricos asimismo tenían lugar de manera casual, corriendo suerte alterna.
Así, en el año 1780 se recuperó, según Matute (1827: 28):

“...en las cercanías de su Foro. Por lo ménos, en el sitio que ahora llaman los Palacios se encuentran tantos fragmentos de obras magníficas, que no podemos dudar que pertenecieran á ellas; y aun á mediados del siglo próximo pasado se veía una gran pieza levantada de norte á sur que llamaban la Armería de Trajano, y otros indicios de suntuosa fábrica, que el terremoto de 1755 acabó de destruir. De este sitio de los Palacios se han sacado los bellísimos fragmentos de estatuas que copiamos; de allí tozos de hermosas columnas, capiteles y otros adornos...

Bien podrán atribuirse a una estatua colosal de César unas corpulentas piernas, que de allí se sacaron año de 1780 , cubiertas por la espalda con el paludamento y apoyadas en basa igualmente de mármol... Hoy se conserva este trozo en la galería de este real Alcázar, cual le presentamos en la lam. 6. núm. 3".

Como fácilmente se constata se trata de las piernas de estatua colosal en traje militar de época adrianea (León 1995: n $^{\circ} 10$ ), que es descubierta en la misma zona de Los Palacios donde se recuperaron los anteriores pedestales citados de estatuas imperiales del siglo III d.C.

En ese mismo lugar prosiguen los trabajos al año siguiente de 1781, que debieron empezar a fines de octubre (Zevallos 1886: 131), y los resultados son aún más sorprendentes, como se refiere en la carta que el propio Francisco de Bruna envía al Conde de Floridablanca en 17.11.1781 y que se transcribe en nuestro Apéndice documental (A): se trata de un especie de exedra rectangular de -según las medidas aportadas por Brunaaproximadamente $3.50 \mathrm{~m}$ de anchura conservado, 2.25 $\mathrm{m}$ de profundidad y 2,25 $\mathrm{m}$ de altura de los muros, que se recubrían con losas marmóreas, al igual que el pavimento (un opus sectile), pero que, según las medidas que indica Zevallos en su obra -“...tenía como ocho varas de largo y seis de ancho" (Zevallos 1886: 131)-, las dimensiones serían de 6.80 x $5 \mathrm{~m}$ de anchura y profundidad. Aunque Bruna no indica en qué sitio exacto tienen lugar los trabajos, el mismo Zevallos dice de forma clara, tras citar los descubrimientos de los tres pedestales antes citados de Los Palacios, que:

"Ultimamente se hallaron el día 2 de Noviembre del año 1781 en el mismo sitio los troncos de dos estatuas... se encontro juntamente un pedestal, que parecía (según su inscripción) perteneciente á la estatua de mujer... Quatro días despues, siguiendo en busca de las cabezas, y demas partes de las estatuas, se dio con el pedazo inferior del otro pedestal perteneciente 


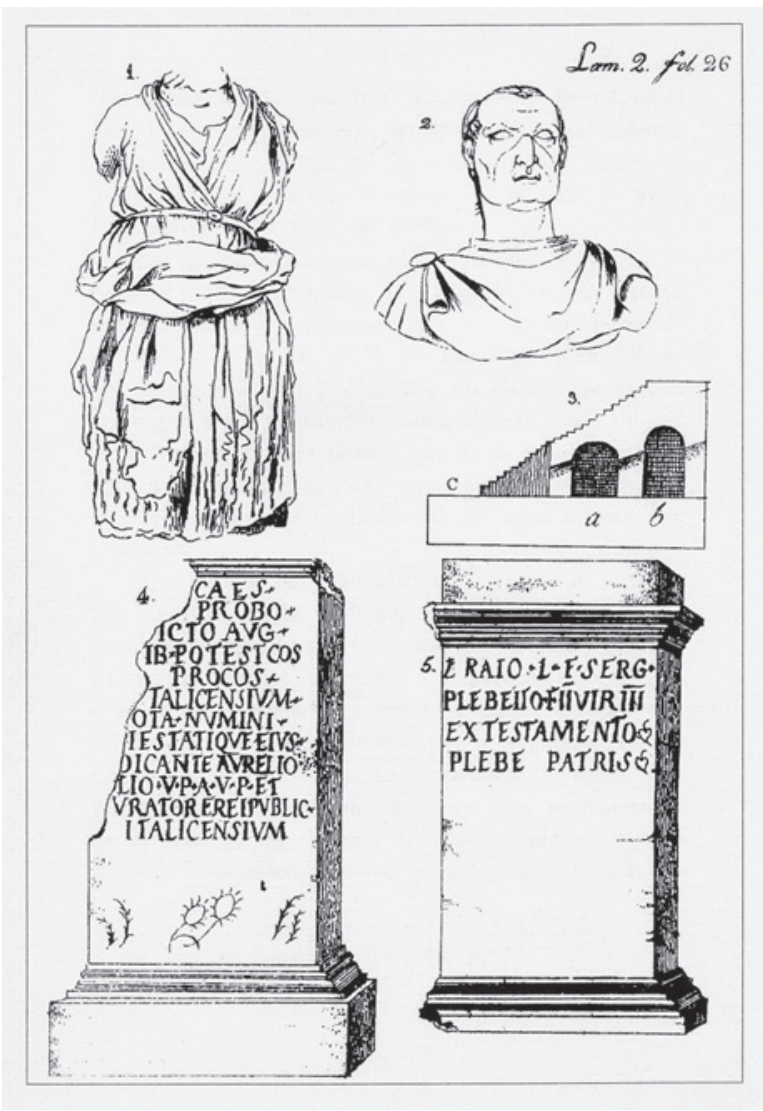

Figura 1. Dibujos de inscripciones, esculturas y sección del anfiteatro de Itálica, según Matute 1827: lám. 2, fol. 26.

a la estatua de hombre... Estos pedestales y troncos de estatuas los llevo el Sr. D. Francisco de Bruna al Alcázar de Sevilla..." (Zevallos 1886: 26s.) .

No cabe duda por las descripciones que la estatua femenina es realmente el magnífico torso de Ártemis o Diana (MAS nº inv. REP 100; León 1995: nº 39) (Fig. 1) y el masculino el de Meleagro (MAS n ${ }^{\circ}$ inv REP 99; León 1995: $n^{\circ} 34$ ), ambos pertenecientes al programa estatuario adrianeo, mientras que los pedestales -que no les corresponden- corresponden al dedicado a Aelia Licinia Valeriana y el de Gavinio Mucro . Tradicionalmente se ha interpretado como parte de un mausoleo por la misma identificación de Zevallos, quien refiere que: "Era magnifica la obra deste sepulcro" (Zevallos 1886: 131), junto al hecho de que en la inscripción del pedestal dedicado a Aelia se mencione que el ordo italicense le haya decretado los gastos del entierro, el lugar de la sepultura y una estatua, por lo que asimismo se ha apuntado que pudieran ser retratos que adoptaban la consecratio in formam deorum (Wrede 1981).

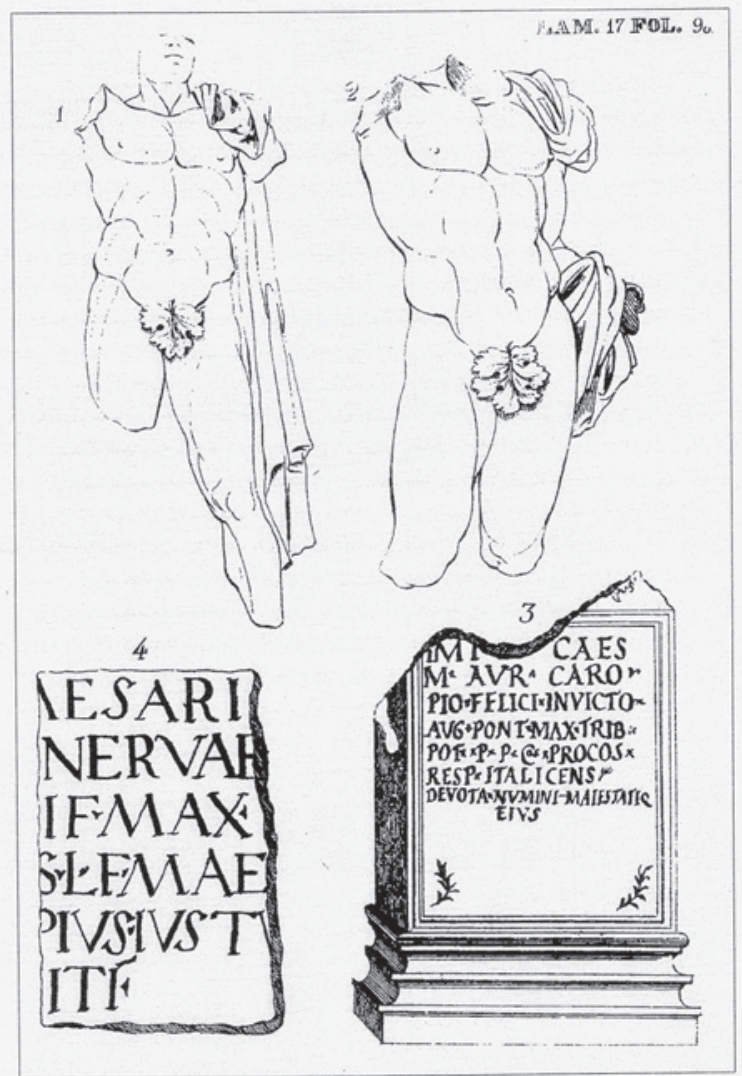

Figura 2. Dibujos de inscripciones y estatuas imperiales de Itálica, según Matute 1827: lám. 20, fol. 90.

No obstante, es muy fuerte el inconveniente que supone el carácter de las estatuas, sobre todo la de Diana, de tamaño mayor al natural y de una calidad que apunta mejor a un ambiente público. Además, la inscripción no implica que la estatua de Aelia que coronaba el pedestal debiera estar obligadamente en el propio mausoleo, sino que pudo situarse mejor en un lugar público, para dejar constancia general del honor recibido. Finalmente, el que proceda del lugar de Los Palacios, que identificaremos posteriormente con el foro italicense, $y$ el carácter de las dos esculturas, poco apropiadas para un ambiente funerario privado, apuntan a que debería no mantenerse esa identificación hipotética .

La certeza de que nos encontramos ante estas dos esculturas se corrobora porque éstas serán incluidas en el famoso dibujo que Antonio Ponz situó en el volumen XVII de su Viage de España y donde seleccionó las cuatro mejores esculturas de la colección de Bruna en los Alcázares (Ponz 1792: carta V, dibujo junto a párrafo 12) (Fig. 3). En ese mismo dibujo se incluyen las otras dos estatuas italicenses seleccionadas, que junto a 


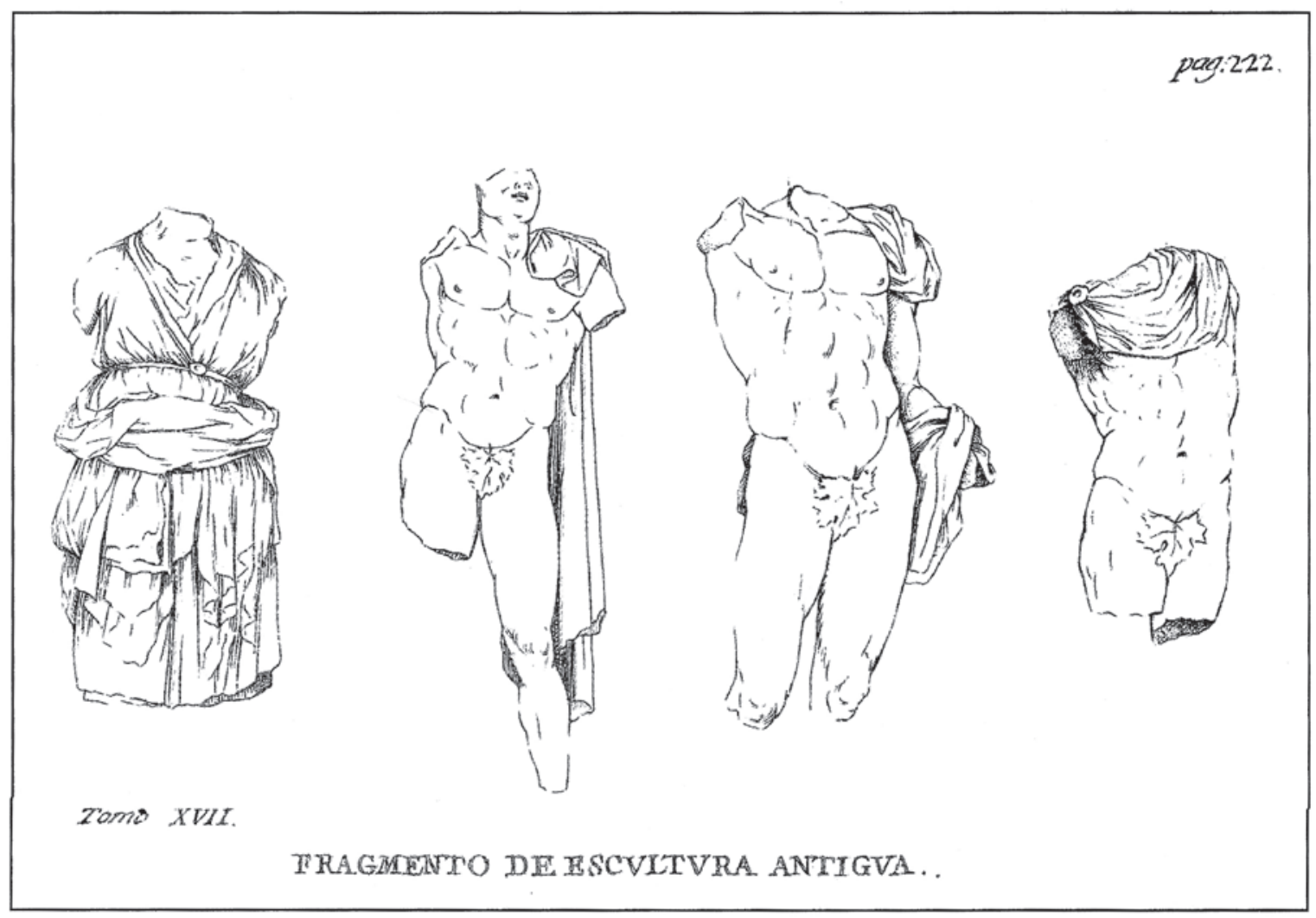

Figura 3. Dibujos de esculturas de Itálica, según Ponz 1792: carta $\mathrm{V}$, dibujo junto a párrafo 12 .

las dos anteriores son para el académico “...lo más noble y excelente que desde aquel paraje, eso es, desde la misma Itálica o Santiponce se ha hecho trasladar por el señor Bruna, son cuatro fragmentos de la mejor escultura antigua que se pueda imaginar hallados el año pasado de 1788..." (Ponz 1792: carta V, párrafo 12): corresponden a la de Trajano deificado y otro soberbio torso considerado tradicionalmente como Adriano, aunque ahora se reclama que sea asimismo representación del mismo emperador Trajano por cuestiones iconográficas (Ojeda 2008 y 2009 a). Según se deduce de la cita anterior, Ponz visitó la colección formada por Bruna en el Alcázar en 1789. A ambas esculturas alaba en la misma línea Matute, pero identificándolas como efigies probables de Nerva y Trajano, dibujándolas junto a una inscripción monumental de carácter imperial, que él piensa dedicada al mismo Nerva (Fig. 2):

“...fragmento colosal de bellísimo mármol, hallado entre las ruinas de Itálica al sitio que nombran los Palacios en año de 1788, el cual quizás figure al mismo
Trajano ó a Nerva en aspecto de deidad... No léjos del sitio en que se encontró este trozo se halló á los pocos días un pedazo de tabla de hermoso mármol pario, que puede probablemente atribuirse al monumento que se erigió en honor del emperador Nerva... la losa, así como la estatua, se condujeron a este Real Alcázar... haberse encontrado junto a este fragmento de estatua otro de igual tamaño y perfeccion en aptitud heroica, me hace sospechar que ámbas se erigieron con un mismo motivo; y si una representaba a Nerva, la otra pudo ser de Trajano... puede conjeturarse que ambas estuvieron colocadas en el foro de Itálica... Se trasladó así como la compañera á este Real Alcázar..." (Matute 1827: 89s.).

Los datos conservados en las cartas que reproducimos íntegramente en el Apéndice documental (B, cartas 1-3) demuestran que las excavaciones fueron hechas por los monjes del monasterio, o al menos éstos tenían en su poder ambas esculturas en el momento que las solicita Bruna para la colección del Alcázar, a los que acusa además de "echar a los hornos de cal" restos 


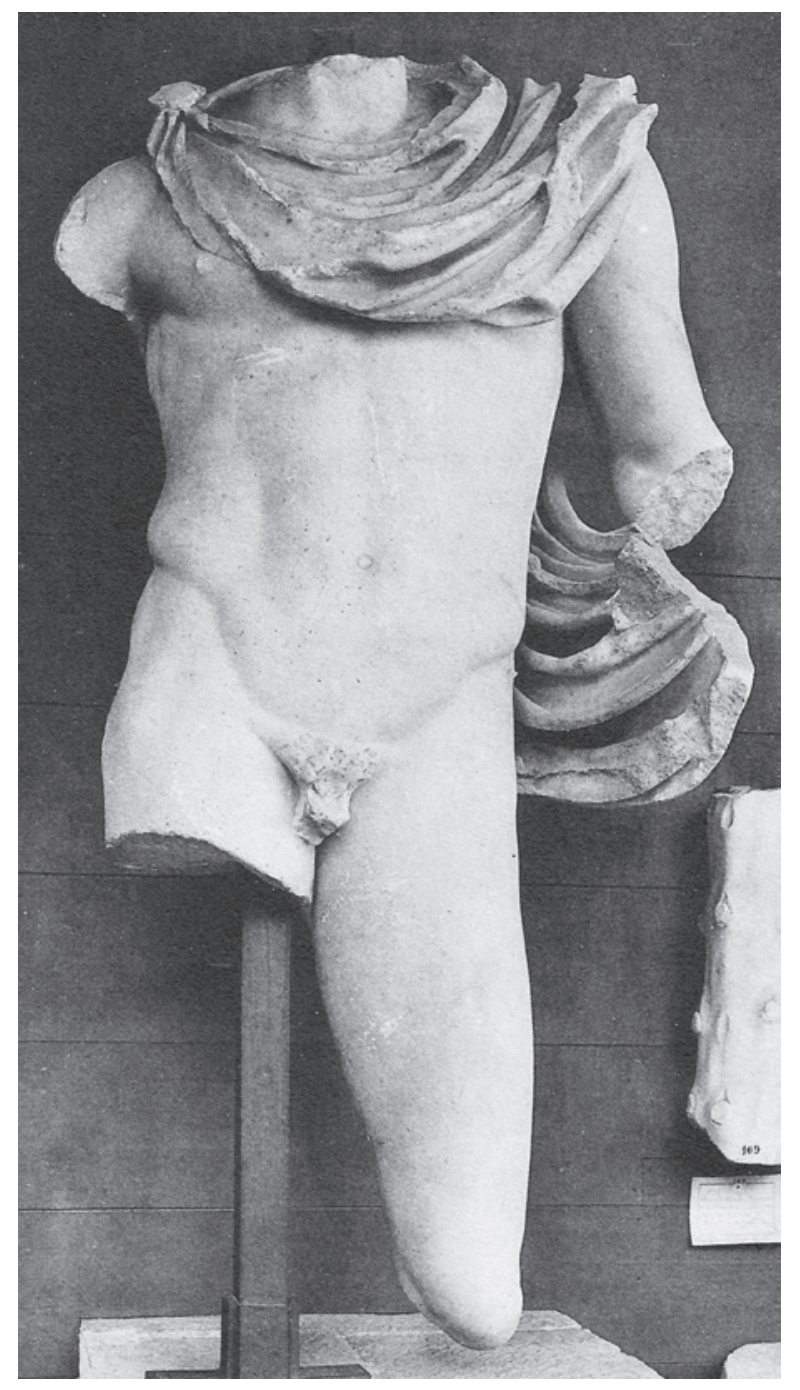

Figura 4. Torso del Hermes Dionysophoros de Itálica, en el Museo Arqueológico de Sevilla del exconvento de la Merced, antes de incorporarle la pierna derecha, tal como fue recuperado en el siglo XVIII.

arqueológicos de mármol. Por el contrario, no hay referencias sobre el momento y sitio exactos en que aparecería el torso del Hermes Dionysophoros (León 1995: $\mathrm{n}^{\mathrm{o}}$ 32) (Fig. 4); aunque tradicionalmente se ha indicado que apareció asimismo en los trabajos de 1788, esa referencia parece comenzar sólo en 1878, cuando Francisco María Tubino la estudia, junto a otra femenina que asimismo se considera italicense y a la que nos referiremos más adelante, pero ello lo hace sólo de una manera genérica y sin aportar ninguna fuente concreta:

“También ordenó Bruna que se hicieran excavaciones en el despoblado de Itálica... Entre las estatuas desenterradas en 1788 por los cuidados de Bruna..." (Tubino 1878: 161).

Por el contrario, en los autores del siglo XVIII nunca se había indicado ese hecho, ni se dibuja la pieza, ni tampoco lo cita un autor como Demetrio de los Ríos, buen conocedor de las antigüedades italicenses, según se constata en la referencia que de ella hace cuando ya se conserva en los fondos de lo que será el Museo Arqueológico de Sevilla. No obstante, parece que no cabe duda de que formó parte de la colección de Bruna en los Alcázares, aunque tampoco aparece en la fotografía en que se reproduce parte de las piezas colocadas en el suelo del nuevo edificio del Museo de Antigüedades en el exconvento de la Merced. Por otro lado, el hecho de que en 1901 apareciera la pierna derecha de la estatua en el complejo arquitectónico de época adrianea del sector NE de la llamada Vetus Urbs parece apuntar a que asimismo de esa zona procedería el fragmento de estatua de Mercurio recuperado en el siglo XVIII.

\section{LA LOCALIZACIÓN DE LOS TOPÓNIMOS CITADOS}

El topónimo de Los Palacios es identificado por el padre Zevallos como un Palacio imperial, que "en las principales ciudades del Imperio estaba prevenido para hospedar al Emperador, quando venía á visitar la provincia", afirmando asimismo que "nadie duda donde estuvo; porque duran hasta hoy con el nombre soberbios pedazos destas, Cornisamientos, Capiteles y otros destrozos de edificios... En el sitio que digo de Itálica, llamado hoy los palacios, vimos hasta el último terremoto del año 1755, una gran pieza levantada de Norte á Sud, y se llamaba la armería de Trajano..." (Zevallos 1886: 88)

Parece, pues, deducirse que en el siglo XVIII Zevallos ubicaba en un mismo sitio Los Palacios, el Palacio y la Armería de Trajano, pero aunque él tuviera clara su ubicación los destrozos posteriores hicieron perder el conocimiento del lugar exacto, e incluso el propio Matute parece que se confunde en varias partes de su obra, como cuando afirma que la columna que se conserva todavía en la entrada del monasterio de San Isidoro fue hallada en1802 en el sitio de Los Palacios, donde se situaría el palacio y junto a éste el foro (Matute 1827: 29s.), pero más adelante la vuelve a citar como aparecida en la llamada Era del convento, junto al teatro (Matute 1827: 33).

Se pueden establecer tres hipótesis principales para la localización de aquellos topónimos citados, como recoge Rodríguez Hidalgo (2009 a: 15ss.): 
- La más lógica fue pensar que se ubicaron en el precisamente llamado actualmente como cerro de los Palacios, al oeste del denominado a su vez como cerro de San Antonio, identificándose exactamente con las llamadas termas Menores (García y Bellido 1960: 102), construidas en época trajanea (León 1977-1978; Roldán 1993: 121-132; Hidalgo 2003:101-103). Según ello sería la decoración escultórica de aquellas termas forenses.

- Una segunda opción ha sido identificar el topónimo con el Traianeum, excavado en la década de 1980 (León 1988), al considerar apropiado este tipo de escultura pública para la decoración de ese ambiente central de la ampliación adrianea. Seguramente deba descartarse esta opción dado que el contexto arqueológico del Traianeum apunta a un gran expolio tras su abandono ya en momentos tardoantiguos y a la ausencia de elementos escultóricos significativos, según demuestran los resultados de las excavaciones citadas.

- Finalmente, se apunta que el Palacio debe situarse en el nordeste del espacio intraurbano, en un sitio privilegiado de la Vetus Urbs de momentos adrianeos, situado sobre el teatro (Beltrán 2009 a: 34 ss.), que es descrito como una edificación de "planta rectangular, sin descartar otras piezas que se le adosan... articulado en su perímetro exterior, al igual que sucede en el Traianeum y la Palestra de las Termas Mayores, por exedras semicirculares" (Rodríguez Hidalgo 2009 a: 17). En este caso serían argumentos a favor la cita antes referida de la columna erigida en el monasterio, extraída de los Palacios en 1803, junto al teatro (Matute 1827: 29s. y 33), así como el hecho de que de esa zona debió extraerse el cuerpo de Mercurio -pues la pierna derecha apareció efectivamente allí en 1901-y otras esculturas en fecha posterior, como la Diana o la Venus y la reciente cabeza de deidad con diadema.

No obstante, creemos que la localización del topónimo de los Palacios debe situarse mejor donde tradicionalmente se localizó, en el llamado cerro de los Palacios, que habría conservado el topónimo, aunque no exactamente en las termas Menores sino asimismo en los edificios y espacios del foro que se situaría exactamente al oeste del edificio termal forense . El argumento concluyente nos lo ofrece asimismo un texto del siglo XVIII, el relato de su visita al yacimiento que realiza Francisco Pérez Bayer en su Diario en el año 1782, un año después de los primeros descubrimientos importantes en los Palacios, como se dijo. Así ha sido puesto de relieve por P. León (1993: 42-43) y J. M. Luzón (2003: 58s.), identificando ambos correctamente a nuestro juicio la secuencia de edificios que relata el erudito valenciano. La descripción de Pérez Bayer es la siguiente:

"Fuimos desde allí al monasterio del lugar. Sobre el cerro a cien passos azia Poniente hay una pequeña colina y varios frogones y ruinas antiguas. En ese sitio se hicieron el año próximo pasado de 81 alg. excavacionesy sacaron alg. inscripciones con RESP. ITALICENSIUM y troncos de bellas estatuas que se trasladaron al Alcázar de Sevilla y estuvieron en el salón destinado a estas antiguallas... Existen aun en el sitio de estas excavaciones una bella caña de columna y un capitel corintio y otras piedras...

Desde esta colinita bajando entre Poniente y Norte hay otro pequeño valle; y de el vuelve a empinarse suavemente otra colinita plantada de olivos como a 200 passos se acaba de subir. De allí a 50 passos de la vereda por donde se baja se descubren a mano diestra ruinas antiguas que muestran haber sido arcos y aquello cañería o aqueducto. Al fin de la bajada o declive de la colina en un valle bastante menos desaogado están las ruinas del celebre anfiteatro..." (Pérez Bayer 1782: 237ss.).

El recorrido se puede seguir, por ejemplo, en el plano que en 1902 realizó Pelayo Quintero Atauri, encargado de hacer el estudio de los mosaicos de Itálica (Luzón 1999: 133ss.) (Fig. 5), y realmente coincide con el que será el posterior trazado de la nueva carretera de Extremadura - actual avenida de Extremadura-, que bordeará por el oeste el área construida de Santiponce en el siglo XIX. Partiendo desde el monasterio, en la esquina inferior derecha, y en dirección hacia el oeste, como cien pasos, aunque debieron ser algunos más, se encuentran los "frogones y ruinas antiguas" donde se habían desarrollado las excavaciones de 1781, en Los Palacios, lo que sitúa efectivamente el lugar hacia la zona del cerro de los Palacios, al sur o este de las termas Menores, como indican asimismo los autores antes referidos (León 1993: 43; Luzón 2003: 58). Se describe a continuación la bajada y vuelta a subir de la cañada Honda y, a mano derecha, restos que quizá correspondan a la casa de la Exedra, para llegar finalmente al Anfiteatro. Las orientaciones que Pérez Bayer indica y las distancias referidas invalidan el que se piense que corresponde al camino real, al pie de Santiponce en la zona baja próxima al río. En un interesante plano del término de la villa de Salteras de 1757, conservado en el archivo de la Catedral de Sevilla (Luzón 1999: 23) se advierte en un detalle ese mismo camino que sale del 


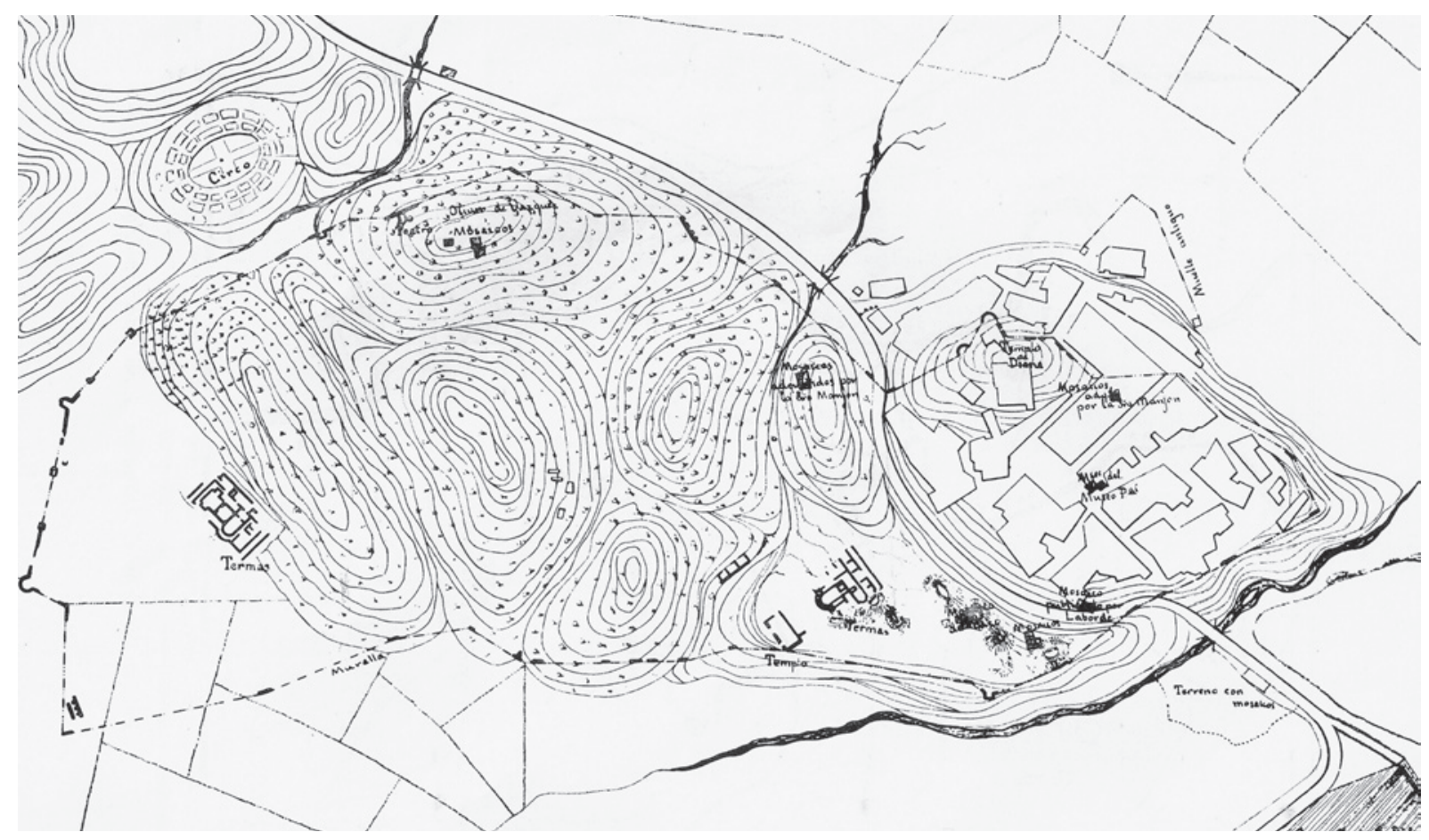

Figura 5. Plano de Itálica, bajo Santiponce, que en 1902 realizó Pelayo Quintero Atauri.

monasterio y conducía hacia el anfiteatro, cruzando al oeste de Santiponce (Fig. 6).

Nos parece, pues, evidente que la mayor parte de los descubrimientos escultóricos y epigráficos llevados a cabo a lo largo del silgo XVIII en Itálica lo fueron especialmente en ese sector de los Palacios que -como tradicionalmente se ha dicho- debía identificarse con el foro italicense y edificios anexos, entre los cuáles las termas, y a cuyo contexto es apropiado el carácter de las inscripciones honoríficas e imperiales, que llegan hasta el siglo III d.C., y los programas escultóricos imperiales, de época adrianea. Será en ese mismo entorno

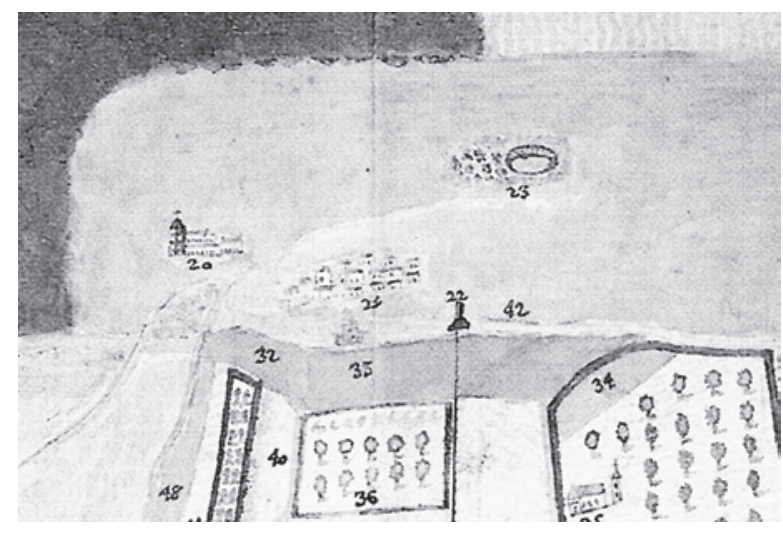

en el que todavía en 1839 excavó Ivo de la Cortina, complementando asimismo los descubrimientos escultóricos adrianeos con piezas de datación anterior, que formaron parte de programas públicos forenses del siglo I d.C. La existencia del topónimo actual del cerro de los Palacios adquiere así pleno significado.

Debemos decir, no obstante, que también se harían algunas excavaciones durante el siglo XVIII en el otro sector citado del NE de la ciudad, en ese nuevo espacio público de época adrianea, ya referido, si nos atenemos al hecho de la localización allí de la escultura de Mercurio que se dice aparecida en esa centuria.
Figura 6. Detalle de la zona del monasterio de San Isidoro del Campo ( $\left.{ }^{\circ} 20\right)$, Santiponce $\left(n^{\circ} 21\right)$ y el anfiteatro de Itálica $\left(\mathrm{n}^{\circ} 23\right)$, en un plano del término de la villa de Salteras de 1757, conservado en el archivo de la Catedral de Sevilla. 


\section{UNA ÚLTIMA HIPÓTESIS: ¿ESTATUA FEMENINA DE ILIPA (ALCALÁ DEL RÍO)?}

Formó parte de la colección arqueológica conformada por Bruna en el Alcázar sevillano una estatua femenina vestida (Fig. 7), que asimismo se hace proceder de Itálica, aunque esa circunstancia se remonta sólo a la segunda mitad del siglo XIX, como hace D. de los Ríos y, además, F. M. Tubino, que la publica junto a la ya citada del Mercurio o Hermes Dionysophoros, considerándolas a ambas como Flora y Apolo respectivamente (Tubino 1878). No obstante, ninguna otra fuente la refirió como aparecida en Itálica, pero como asimismo ocurre con el caso de la estatua masculina, que sí es italicense sin duda. Además, la estatua femenina fue dibujada por Alexandre de Laborde en su obra Descripcion de un pavimento de mosaico descubierto en Italica (Madrid 1806), que reproduce J. M. Luzón (1999: 56), entre las esculturas imperiales de Itálica (Fig. 8), aunque ello sólo asegura que en esos momentos se encontraba en la colección del Alcázar, pero no que fuera de procedencia segura italicense, ya que en aquella colección tuvieron cabida estatuas de otras procedencias.

Precisamente la duda se plantea al leer una referencia de Antonio Ponz en su citado volumen XVII del Viage de España, cuando al describir la colección de Bruna en el año de 1789, dice lo siguiente:

\footnotetext{
"También ha venido recientemente a esta colección una estatua de mujer alticincta; cosa excelente, pero asimismo sin cabeza ni brazos. Los paños con que está cubierta no impiden para conocer su desnudo excelente; es de siete palmos y se ha encontrado, a cinco varas de profundidad, en Alcalá del Río, dos leguas distante de Sevilla" (Ponz 1792: carta V, párrafo 14).
}

Si ello fuera así habría que descontar de la nómina de la estatuaria italicense esta pieza y agregarla a la de Ilipa (Alcalá del Río, Sevilla). Coincide con la escultura citada la valoración de que los paños de la túnica insinúan las formas corporales y, sobre todo, la referencia al cinto alto que recoge túnica y estola bajo los senos, si bien la altura indicada de siete palmos -aproximadamente $1,5 \mathrm{~m}$ - es insuficiente para la altura de $1,85 \mathrm{~m}$ que presenta la pieza que citamos. Quede, pues, como simple hipótesis a tener en cuenta en el futuro.

Figura 7. Estatua femenina vestida, que se hace proceder de Itálica. Museo Arqueológico de Sevilla. Foto: autor

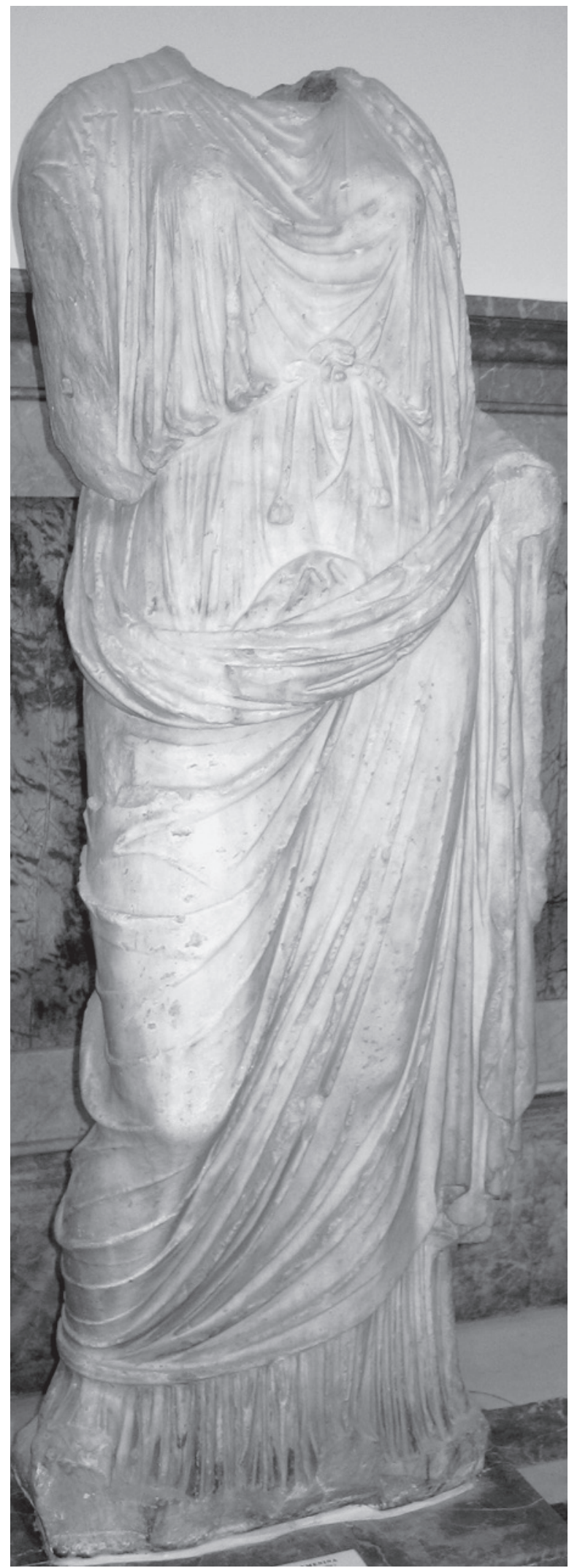

SPAL 17 (2008): 47-59 

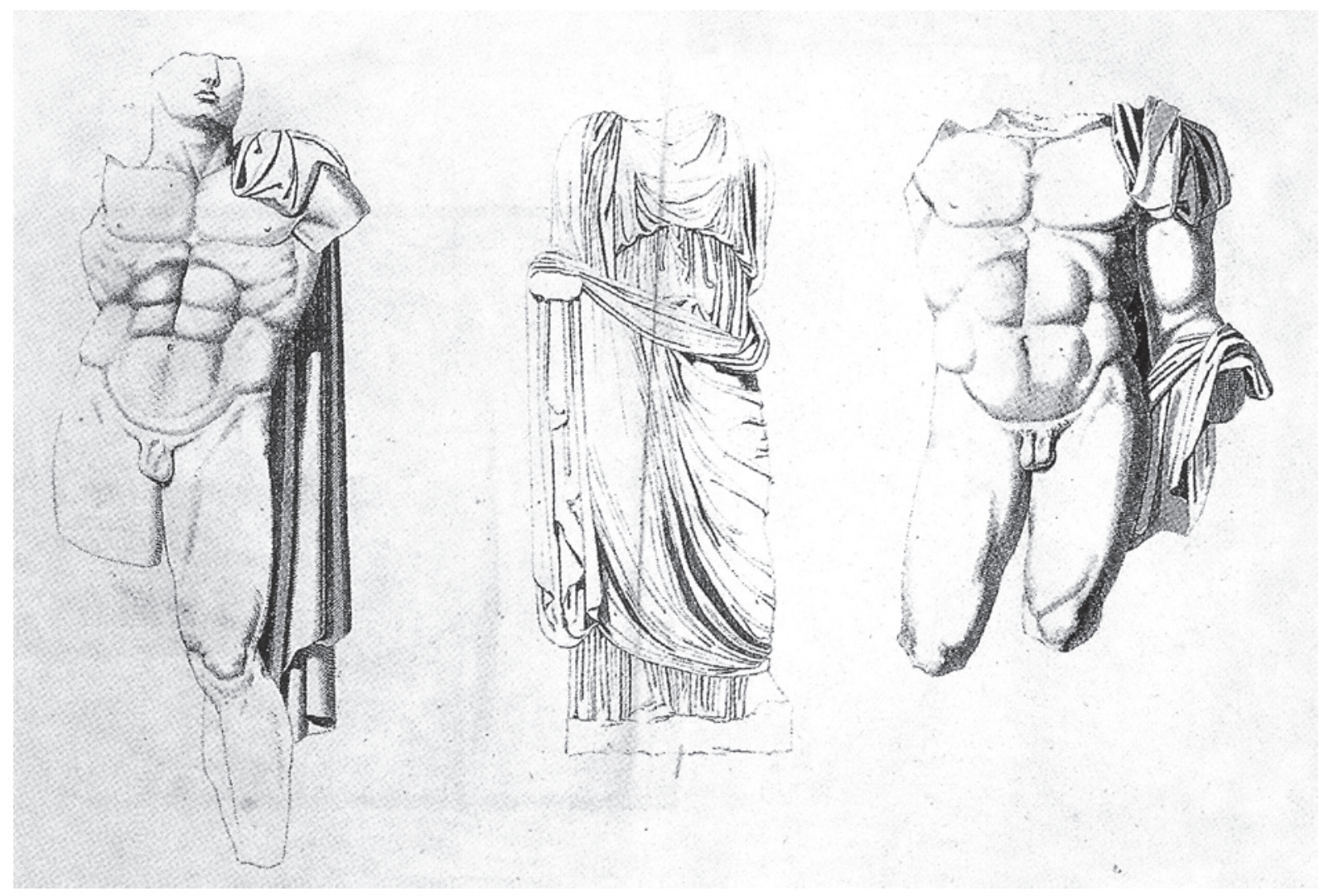

Figura 8. Dibujos de la estatua femenina anterior, junto a las estatuas imperiales de Itálica, según Laborde 1806.

\section{APÉNDIDE DOCUMENTAL}

\section{A) Archivo General de Simancas. Secretaría de Hacienda, leg. 992. Los dibujos en la sección Mapas, Planos y Dibujos, VI-51 y 52.}

1) Carta de F. de Bruna al Conde de Floridablanca (17.11.1781) .

"Excelentísimo Señor

Muy Señor mío: Me ha parecido digno de noticia de V.E. el aviso que con motivo de una excavación que se está haciendo en el lugar de Santiponce, distante una legua de Sevilla, en el terreno de la antigua Itálica, se descubrió un hueco de cuatro varas y medio palmo de largo, dos y una tercia de ancho y dos y una tercia de alto; sus paredes de ladrillo romano cubiertas con enchapaduras de losas de mármol y jaspes muy finos de una tercia, y en los intermedios labores de mosaicos de piezas de vidrio de seis colores (las blancas, doradas por la superficie) del tamaño de dados fijados en argamasa. El pavimento estaba cubierto de losas de mármol de dos varas y media de largo y dos palmos y medio de ancho entre fajas de la misma piedra, y por el contorno de él hacia la pared losas de a tercia blancas y negras.

Dentro se encontró una columna rota en tres pedazos, de 27 pulgadas de diámetro y 7 varas y 24 pulgadas de alto con la base y capitel corintio de mármol muy fino, una cornisa dórica y dos pedestales de estatuas: uno perfectamente conservado con su inscripción, y una parte de otro en que se lee con claridad el nombre del sujeto y el pueblo; con la singularidad de que parece según las letras iniciales, se llamó Colonia Victrix Italica, como lo había pretendido en tiempo del emperador Adriano, que hasta ahora todos los monumentos y medallas decían municipio.

Se encontraron también las dos estatuas de los dos pedestales, de mármol muy blanco y fino, de particular escultura, la una de mujer, mayor del tamaño natural, con su pretexta enrollada con gran arte al cuerpo hasta mitad del muslo, y desde allí hasta el principio de la pierna se figura otra ropa interior como de pieles, con su aljaba a la espalda, pero le faltan la cabeza, brazos 
y piernas. La otra estatua de hombre de igual mármol y perfección es desnuda, con la pretexta cogida al principio del pecho y primer tercio de la espalda, está también sin cabeza, brazos ni piernas.

Por más cuidado que se ha puesto desde que se tuvo la noticia, cuando ya se había hecho parte de la excavación, habiendo yo ido diferentes tardes a presenciarla, no se han podido encontrar las cabezas, pies ni manos, y sólo se han recogido entre aquellas ruinas trozos que manifiestan ser de los brazos y piernas, y se está examinando cómo podrán acomodarse; habiéndose sacado con no poco trabajo del hoyo la columna por su gran mole.

Las losas y jaspes de la enchapadura de la pared estaban cubiertas de tierra, al hacerse la excavación al principio con menos cuidado se hicieron menudos pedazos porque sólo con los dedos se rompían al más leve golpe; sin embargo, he podido recoger algunas enteras de varios colores, que así que les ha dado el aire se han endurecido. Se hallaron también pedazos de tinaja de mármol rosado, y entre huesos casi petrificados una sortija cubierta de herrumbre, que parece por lo que se descubre ser de metal corintio, con unas letras en lo que hace de frente que pueden decir AELIA.

He conducido a este Alcázar los pedestales y estatuas que he colocado en el mismo salón donde están los modelos de yeso y demás inscripciones de la Bética. También he recogido diferentes losas y jaspes y el anillo; e incluyo a V.E. copia de las inscripciones.

Nuestro Señor guarde a V.E. muchos años como deseo. Sevilla y noviembre 17 de abril de 1781 .

Excelentísimo Señor. Beso la mano de V.E., su muy atento servidor D. Francisco de Bruna.

Excelentísimo Señor Conde de Floridablanca"

B) Archivo del Real Alcázar de Sevilla. Caja 153, expte. 1: "Papeles sobre conducción a los Reales Alcázares de Estatuas colosales, halladas en Santiponce, al sitio de la antigua Itálica, y de otra sobre traer a ellos una lápida romana encontrada en La Carlota".

1) Carta de Bruna a Floridablanca (15.10.1788):

"Muy Señor mío: Con las noticias de haberse encontrado dos estatuas colosales en el lugar de Santiponce una legua de esta ciudad, que era el sitio de la antigua Itálica, donde está situado el monasterio de Gerónimos, que son señores espirituales y temporales de aquel pueblo, pasé a verlas el domingo próximo pasado y las encontré en un corral de el monasterio lleno de broza, donde las habían puesto tendidas en el suelo: son dos estatuas colosales de mármol blanco muy fino de singular escultura, que me persuado sean de las mejores que se hayan descubierto. Están desnudas sin más que la pretexta a la espalda, cogida con un botón por el pecho: la una, que está boca arriba, es idéntica al Apolo de Belvedere; la otra, que está boca abajo, no la pude reconocer, porque son de un extraordinario tamaño y peso. También vi un pedestal hermosísimo de piedra azul con inscripción muy bien conservada, que copié, acabado de encontrar.

Las pedí al prior, para colocarlas en el Salón entrando de los Jardines del Alcázar donde tengo puestas las estatuas e inscripciones de la Bética, que he podido recoger, algunas de ellas que me han franqueado los mismos monjes, pero ahora se regatean porque han oído a las gentes ponderarlas. Sería un dolor que esto no se traiga a este Palacio del Rey, donde estarán bien conservadas y se podrán reparar de algunos fragmentos que les faltan, en caso de no encontrarlos en el paraje de donde se sacaron, dejándolas expuestas a que hagan con ellas lo mismo que con otros trozos de antigüedades, que los han echado a los hornos de cal, haciendo de las hermosas columnas de jaspes raros, que han hallado por casualidad labrando la tierra, gradas y otras piezas, aserrándolas por la poca curiosidad e inteligencia de aquellos monjes.

Suplico a V.E. se sirva dar la orden para que se trasladen a este Palacio del Rey, y en caso de que lo tenga por conveniente, sería muy oportuno que fuese antes de que empezasen las aguas, porque el camino es muy pantanoso, las estatuas son de una gran mole y será imposible traerlas hasta la primavera próxima, quedando expuestas a que las maltraten más.

V.E. resolverá lo que fuese de su superior agrado. Nuestro Señor guarde a V.E. m(uchos). a(ños). Sevilla, 15 de octubre de 1788.

Excelentísimo Señor Conde de Floridablanca"

\section{2) Carta de respuesta de Floridablanca a Bruna} (27.10.1788):

"Estado.

En vista de su carta de V.S. de 15 del corriente, quiere el Rey se conduzcan luego las estatuas halladas en el Monasterio de Santiponce a ese Real Alcázar de Sevilla, y que reconozcan y declaren el mérito de su escultura los Profesores a fin de que, si son tan excelentes como V.S. me dice, se trasladen a Madrid, en donde determina S.M. que se coloquen. Para este efecto, prevengo en esta fecha al prior la voluntad y resolución del Rey, para que lo tenga entendido, y a V.S. se lo participo para su cumplimiento.

Dios guarde a V.S. m(uchos). a(ños). San Lorenzo 27 de octubre de 1788. El Conde de Floridablanca.

Señor D. Francisco Bruna" 


\section{3) Segunda carta de Bruna a Floridablanca (08.11.1788):}

"Excelentísimo Señor

Muy Señor mío: Recibí la de V.E. de 27 del pasado, en que se sirvió prevenirme que en vista de lo que yo había avisado en 15 del mismo mes, quería el Rey se condujesen luego las estatuas halladas en el monasterio de Santiponce a este Real Alcázar, y que reconozcan y declaren el mérito de su escultura los Profesores, a fin de que si son tan excelentes como yo decía, se trasladen a Madrid, donde determina S.M. que se coloquen; y con la misma fecha prevenía V.E. al prior la voluntad y resolución del Rey para que lo tenga entendido.

Al día siguiente de recibir la orden de V.E. fui a Santiponce y puesto de acuerdo con el dicho prior he dado providencia pronta para traerlas a este Alcázar con no poco trabajo, porque son de un peso extraordinario, y ya quedan en el día de hoy en este Palacio; las reconocerán los profesores y avisaré a V.E. y siempre es menester esperar que llegue el mes de abril, para hacer una excavación en el mismo sitio donde se encontraron, que fui a registrar y era a una vara flor de tierra tendidas, para buscar los pedazos que les faltan y los pedestales si los tuvieren.

Nuestro Señor guarde a V.E. m(uchos). a(ños). Sevilla y noviembre 8 de 1788 .

Excelentísimo Señor Conde de Floridablanca"

\section{BIBLIOGRAFÍA}

AAVV (2002): San Isidoro del Campo (1301-2002). Fortaleza de espiritualidad y santuario del poder, catálogo de la exposición. Consejería de Cultura de la Junta de Andalucía, Sevilla.

ARRIBAS, F. (1950): "Datos y documentos sobre arte procedentes del Archivo General de Simancas. Hallazgos arqueológicos en el siglo XVIII", BSEAA XVI: $195-199$.

BELTRÁN FORTES, J. (2001): "La escultura clásica en el coleccionismo erudito de Andalucía (siglos XVII-XVIII)", El coleccionismo de escultura clásica en España: 143-171. Museo del Prado, Madrid.

- (2003): "La antigüedad romana como referente para la erudición española del siglo XVIII", J. Beltrán, B. Cacciotti, X. Dupré y B. Palma (eds.), Le antichità e $i$ loro protagonisti in Spagna e in Italia nel XVIII secolo: 47-64. L'Erma di Bretschneider, Roma.

- (2009 a): "Italica en época adrianea", J. González y P. Pavón (eds.), Adriano. Emperador de Roma: 2748. L'Erma di Bretschneider, Roma.
- (2009 b): "La nueva diosa de Itálica", Italica. Colina de dioses: 41-47. Catálogo de la exposición, Consejería de Cultura de la Junta de Andalucía, Sevilla.

- (2010): "Las esculturas", A. Caballos (ed.), Itálica - Santiponce. Municipium y Colonia Aelia Augusta Italicensium. L'Erma di Bretschneider, Roma.

BELTRÁN FORTES, J. y LÓPEZ RODRÍGUEZ, J. R. (eds.) (2003): El museo cordobés de Pedro Leonardo de Villacevallos. Coleccionismo ilustrado en la Andalucía del siglo XVIII., Universidad de Málaga Real Academia de la Historia, Málaga - Madrid.

CABALlOS, A. y LEÓN, P. (eds.) (1995): Italica $M M C C$. Consejería de Cultura de la Junta de Andalucía, Sevilla.

CABALLOS RUFINO, A.; MARÍN FATUARTE, J. y RODRÍGUEZ HIDALGO, J. M. (1999): Sevilla Arqueológica. Universidad de Sevilla - Consejería de Cultura de la Junta de Andalucía, Sevilla.

CANO RIVERO, I. (2003): "Ver para aprender. La primera galería pública de Sevilla en el Alcázar (17701807). Aires ilustrados en Sevilla", Mus-A 1: 25-31.

CHISVERT JIMÉNEZ, N. (1987-1988): "Reflexiones sobre el empleo de topónimos y la descripción de edificios italicenses en obras antiguas", Habis 1819: $565-581$.

CILA 3. Sevilla = GONZÁLEZ FERNÁNDEZ, J.: Corpus de Inscripciones Latinas de Andalucía, II: Sevilla. II: La Vega (Italica). Consejería de Cultura de la Junta de Andalucía, Sevilla.

CORTINA, I. de la (1840): Antiguedades de Italica. Sevilla.

FERNÁNDEZ GÓMEZ, F. (1998): Las excavaciones de Italica y don Demetrio de los Rios a través de sus escritos. Caja Sur, Córdoba.

FLÓREZ, E. (1754): España Sagrada. Tomo XII. Madrid.

GARCÍA Y BELLIDO, A. (1960): Colonia Aelia Augusta Italica. CSIC, Madrid.

HIDALGO PRIETO, R. (2003): "En torno a la imagen urbana de Italica", Romula 2: 89-126.

LABORDE, A. de (1806): Descripcion de un pavimento de mosaico descubierto en Italica. Madrid.

LEÓN ALONSO, P. (1977-1978): "Notas sobre la técnica edilicia en Itálica”, AEspA 50-51: 143-164.

- (1988): El Traianeum de Italica, Sevilla.

- (1993): "Las ruinas de Itálica. Una estampa arqueológica de prestigio", J. Beltrán y F. Gascó (eds.), La antigüedad como argumento. Historiografía de Arqueología e Historia Antigua en Andalucía: 29-61. Sevilla.

- (1995): Esculturas Romanas de Italica. Consejería de Cultura de la Junta de Andalucía, Sevilla. 
LÓPEZ RODRÍGUEZ, J. R. (2010): Historia de los Museos de Andalucía (1500-2000). Universidad de Sevilla.

LUZÓN NOGUÉ, J. M. (1999): Sevilla la Vieja. Un paseo histórico por las ruinas de Itálica. Fundación Focus-Abengoa, Sevilla.

- (2003): "Las ruinas de Itálica y el convento de San Isidoro del Campo", J. Beltrán - M. Belén (eds.), El clero y la Arqueología española: 49-62. Universidad de Málaga - Fundación El Monte, Sevilla.

MATUTE Y GAVIRIA, J. (1827): Bosquejo de Itálica ó Apuntes que juntaba para su historia. Sevilla.

OJEDA NOGALES, D. (2008): "El «Adriano» colosal de Itálica", R. Cebrián (ed.), VI Reunión de Escultura Romana en Hispania: 45-46. Cuenca.

- (2009 a): El Trajano de Itálica. Universidad de Sevilla, Sevilla.

- (2009 b): "Torso imperial de Itálica tipo Diomedes", Anales de Prehistoria y Arqueología de la Universidad de Murcia 24.

PEÑA JURADO, A. (2008): "Reflejos del Forum Augustum en Italica”, T. Nogales y J. González (eds.), Culto imperial: política y poder: 323-345. L'Erma di Bretschneider, Roma.

PONZ, A. (1792): Viage de España. Madrid, tomo XVII.

RESPALDIZA, P. (2002): "San Isidoro en el pozo. c. 1656", San Isidoro del Campo (1301-2002). Fortaleza de espiritualidad y santuario del poder: 268270. Catálogo de la exposición, Consejería de Cultura de la Junta de Andalucía, Sevilla.

RODRÍGUEZ GUTIÉRREZ, O. y JIMÉNEZ SANCHO, A. (2009): "La excavación arqueológica”, Italica. Colina de dioses: 48-52. Catálogo de la exposición, Consejería de Cultura de la Junta de Andalucía, Sevilla.

RODRÍGUEZ HIDALGO, J. M. (1991): "Sinopsis historiográfica del anfiteatro de Itálica”, J. Arce y R. Olmos (eds.), Historiografía de la Arqueología y de la Historia Antigua en España (siglos XVIII-XX): 91-94. Ministerio de Cultura, Madrid.

- (2004): "El monasterio de San Isidoro del Campo y las Ruinas de Itálica", Actas Simposio. San Isidoro del Campo 1301-2002: 189-207. Consejería de Cultura de la Junta de Andalucía, Sevilla.
- (2009 a): "«El Palacio de Italica», colina de dioses”, Italica. Colina de dioses: 15-26. Catálogo de la exposición, Consejería de Cultura de la Junta de Andalucía, Sevilla.

- (2009 b): "Mercurio", Italica. Colina de dioses: 2932. Catálogo de la exposición, Consejería de Cultura de la Junta de Andalucía, Sevilla.

- (2009 c): "Diana", Italica. Colina de dioses: 33-36. Catálogo de la exposición, Consejería de Cultura de la Junta de Andalucía, Sevilla.

- (2009 d): "La Venus de Itálica", Italica. Colina de dioses: 37-40. Catálogo de la exposición, Consejería de Cultura de la Junta de Andalucía, Sevilla.

RODRÍGUEZ MORALES, A.; ESCOBAR PÉREZ, B. y GARCÍA VARGAS, E. (1991): "Historiografía de la estatuaria italicense", J. Arce y R. Olmos (eds.), Historiografía de la Arqueología y de la Historia Antigua en España (siglos XVIII-XX): 95-98. Ministerio de Cultura, Madrid.

ROLDÁN GÓMEZ, L. (1993): Las técnicas constructivas romanas en Itálica (Santiponce, Sevilla). Universidad Autónoma de Madrid.

ROMERO MURUBE, J. (1965): Francisco de Bruna y Ahumada. Ayuntamiento de Sevilla.

SALAS ÁLVAREZ, J. (2007): "Coleccionismo erudito en la Andalucía de la Ilustración: los depósitos eclesiásticos de antigüedades", Mus-A 8: 140-144.

SÁNCHEZ SOBRINO, S. (pseudónimo: A. Franco y Bebrinsáez) (1774): Viaje topográfico desde Granada a Lisboa el año de 1774. Granada.

TORRUBIA FERNÁNDEZ, Y. (2006): "El museo arqueológico de Sevilla en el convento de la Merced", Laboratorio de Arte 19: 503-515.

TUBINO, F. M. (1878): "Estatuas de Flora y de Apolo, desenterradas de las ruinas de Itálica, junto a Sevilla", Museo Español de Antigüedades IX: 157ss.

WREDE, H. (1981): Consecratio in formam deorum. Vergöttlichte Privatpersonen in der römischen Kaiserzeit. Mainz.

ZEVALLOS, F. de (1886): La Itálica. Sevilla, impr. José María Ariza.
FECHA DE ENTRADA: 25-02-2010

FECHA DE ACEPTACIÓN: 12-03-2010 